* Doutora em direito das relações sociais pela Universidade Federal do Paraná - UFPR; Mestre em Direito Civil pela Universidade Estadual de Maringá - UEM; Docente no Programa de Mestrado e doutorado da UNICESUMAR, Pesquisadora do ICETI. Membro da IBDFAM e do IAP - Instituto dos advogados do Paraná. Advogada. E-mail: cleidefermentao@gmail.com.

** Mestranda em Ciências Jurídicas pelo Centro Universitário de Maringá - UniCesumar, com enfoque nos Direitos da Personalidade e seu alcance na contemporaneidade. Bolsista do Programa de Suporte à PósGraduação de Instituições de Ensino Particulares (PROSUP/ CAPES). Membra do grupo de Pesquisa "Proteção Integral da Pessoa: Interações dos Direitos Humanos, dos Direitos Fundamentais e dos Direitos da Personalidade"; Pós-Graduanda em Ciência Política; Graduanda em Teologia pela Faculdade Teológica Sul-americana FTSA; graduada em Direito pela Faculdade Maringá. E-mail: karytamp@gmail.com.

\section{A DIGNIDADE DA PESSOA HUMANA E A CRISE DO AMOR LÍQUIDO SEGUNDO ZYGMUNT BAUMAN}

\author{
Cleide Aparecida Gomes Rodrigues Fermentão* \\ Karyta Muniz de Paiva Lessa**
}

Como citar: FERMANTÃO, Cleide Aparecida Gomes Rodrigues; LESSA, Karyta Muniz de Paiva. A DIGNIDADE DA PESSOA HUMANA E A CRISE DO AMOR LÍQUIDO SEGUNDO ZYGMUNT BAUMAN. Revista do Instituto de Direito Constitucional e Cidadania - IDCC, Londrina, v. 4, n. 1, p 176188, ago, 2019. ISSN: 2596-0075.

https://doi.org/10.48159/revistadoidcc.v4n1.fermentao.lessa 


\section{INTRODUÇÃO}

A Dignidade da Pessoa Humana é considerado um tema atual, mesmo que todas as questões que envolvem o termo sejam amplas, complexo e cause inúmeras discussões em inúmeras áreas; sejam filosóficas, religiosas ou científicas. Para encontrar a definição de tal direito, inicialmente um princípio, é preciso buscar compreensão na evolução histórica, e também analisar o modo e o desenvolvimento da sociedade que foi alcançando os direitos da personalidade. A Dignidade da Pessoa humana pode ser considerado um princípio basilar no direito brasileiro, sendo princípio supremo de onde decorrem a maioria dos direitos que garantem o desenvolvimento da pessoa, físico, psíquico, emocional, etc.

O objetivo da presente pesquisa é inicialmente a reflexão filosófica e jurídica da conceituação de Dignidade da Pessoa Humana, a implementação deste no ordenamento jurídico pátrio, e também a análise da crise que se vê hodiernamente em relação às relações sociais, tida por Zygmunt Bauman, como amor líquido. Por consequência do modelo econômico capitalista a sociedade obcecada pelo princípio do consumismo, busca freneticamente a felicidade e se sentir completo e realizado com o consumo exacerbado, voltados ao culto aos valores materiais, onde consumir rápido e descartar mais rápido ainda é basilar.

Neste cenário, o individualismo é propulsor de uma série de atitudes, como os relacionamentos e interações sociais sem nenhum vínculo afetivo e comprometimento com o cuidado, e muito menos de preservar a dignidade do outro, enquanto mais fraco e totalmente dependente dos progenitores. O relacionamento humano será visto como um grande herói frente a toda falta de amor pelo próximo nas relações humanas atuais, tendo em vista que propor-se-á uma autorreflexão de como a entidade familiar é responsável juntamente com o Estado no que tange o respeito à dignidade da pessoa humana dos seres vulneráveis.

O objetivo da presente pesquisa é analisar se o princípio da dignidade da pessoa humana se mostra suficiente e tem sido respeitado para promover e efetivar o direito dos filhos à convivência familiar e ao afeto num mundo de amor líquido.

A presente pesquisa enfrentará a seguinte problematização: É possível dizer que a humanidade já viveu tudo que podia e agora sente a necessidade de se reinventar? O homem diante de incontáveis experiências frustrantes anula-se em sua individualidade, e diante de tal condição é possível dizer que a sua dignidade é violada?

Para responder a tais questionamentos a presente pesquisa fará o exame da dignidade humana e a análise do amor líquido de Bauman, e utilizar-se-á do método Indutivo, consistente na pesquisa de obras e artigos periódicos que abordam problemáticas da crise humana em sua individualidade egoísta, da falta de afetividade na pós- modernidade, do capitalismo, como também dos aspectos teóricos filosóficos da difícil conceituação da dignidade da pessoa humana. 


\section{DO PRINCÍPIO DA DIGNIDADE DA PESSOA HUMANA}

Com o passar do tempo a conceituação de dignidade da pessoa humana foi ganhando forma, e por intermédio de uma ponderação filosófica e pensamento religioso, foi ganhando uma roupagem efetiva para sua preservação. Embora seja praticamente impossível de conceituá-la e delimitá-la, afinal se trata de um princípio norteador, de um valor moral e espiritual atrelado e inerente à pessoa humana. Tem-se ainda como conceito a priori, ou seja, independentemente de sua positivação na legislação, tida como valor próprio da natureza do homem .

Em se tratando do ordenamento jurídico brasileiro, o Princípio da Dignidade humana é o princípio que norteia todo o direito, a começar pelos princípios. Foi constituída como princípio pela atual Constituição Federal de 1988, também é classificada como inerente à vida humana, presente em seu artigo $1^{\circ}$, inciso $\mathrm{III}^{2}$, tem-se que o princípio da dignidade humana é fundamento e de valor incalculável e primordial. Não se pode desconsiderar que este princípio é o elo de todos os direitos fundamentais. Ao entendimento de Ana Paula de Barcellos apenas quando os direitos fundamentais da pessoa humana forem analisados e resguardados é que o homem tem a sua dignidade afirmada ${ }^{3}$.

Em que pese o significado segundo o dicionário Aurélio, dignidade é tida como: “1 - Qualidade de digno; 2 - Modo digno de proceder; 3 - Procedimento que atrai o respeito dos outros; 4 - Brio; gravidade; 5 - Cargo ou título de alta graduação; 6 - Honraria; 7 - Dignitário ${ }^{4}$. De acordo com a explicação de Habermas sobre a dignidade da pessoa humana, ela é tida por uma definição em relação às relações interpessoais onde há a necessidade de reconhecimento recíproco e no relacionamento igualitário interpessoais. Em outras palavras a dignidade humana não é algo que provém de natureza, como ser alto, ou ter cabelos loiros ${ }^{5}$.

Ingo Wolfgang Sarlet traz um viés distinto quanto à conceituação da dignidade da pessoa humana, em relação aos demais. Este traz a perspectiva ontológica juntamente com a busca do aspecto intersubjetivo juntamente com as propriedades positiva e negativa, ou respectivamente defensiva e prestacional.

A qualidade intrínseca e distintiva reconhecida em cada ser humano que o faz merecedor do mesmo respeito e consideração por parte do Estado e da comunidade, implicando, neste sentido, um complexo de direitos e deveres fundamentais que assegurem a pessoa tanto contra todo e qualquer ato de cunho degradante e desumano como venham a the garantir as condições existenciais mínimas para uma vida saudável, além de propiciar e promover sua participação ativa e responsável nos destinos da própria existência e da vida em comunhão

1 GAMA, Guilherme Calmon Nogueira da. O biodireito e as relações parentais: O estabelecimento da parentalidadefiliação e os efeitos jurídicos da reprodução assistida heteróloga. Rio de Janeiro: Renovar, 2003. p.133

2 BRASIL. Constituição Federal de 1988. Brasília, 1988. Disponível em: < hhttp://www.planalto.gov.br/ccivil_03/ Constituicao/Constituicao.htm >. Acesso em: 18 abr. 2019.

3 BARCELLOS, Ana Paula de. A eficácia jurídica dos princípios constitucionais: o princípio da dignidade da pessoa humana. Rio de Janeiro: 2002. p. 110-111.

$4 \mathrm{https}$ //dicionariodoaurelio.com/dignidade. Acesso em: 02 mar 2019.

5 HABERMAS, Jürgen. O futuro da natureza humana. Trad. de Karina Jannini. São Paulo: Martins Fontes, 2004, p. 47 
com os demais seres humanos ${ }^{6}$.

Em breve análise histórica entende-se que foi com o cristianismo que houve um divisor de águas significativo em relação à importância do ser humano. Uma vez que o homem foi criado à imagem e semelhança de Deus, portanto, possui valor inexorável e de maneira alguma poderia ter sua essência alterada para um simples objeto ${ }^{7}$. Um grande personagem foi São Tomás de Aquino, no que tange a liberdade e sua vontade de agir sendo o ser humano aquilo que ele chama do ser racional mais perfeito de toda a natureza, perfeito pois deve se referir a Deus, uma vez que sua essência é perfeita, e este possui dignidade da natureza divina, e seu nome máximo convém a Ele e transcende toda dignidade ${ }^{8}$.

A pessoa pode ser definida por sua consciência e também por sua liberdade, conforme o entendimento de São Tomás de Aquino. Já Immanuel Kant parte do pressuposto de que a dignidade humana é a autonomia ética do ser humano ${ }^{9}$, isto quer dizer que o ser humano é um ser único, e não um objeto, ou um meio. E por ser único, deve merecer tanto consideração, quanto respeito pelo Estado. Para ele, o ser humano é tido como pessoa por possuir valor superior a qualquer preço, uma vez que como pessoa jamais pode ser pensado apenas e simplesmente como um meio para o fim de outrem ou de si mesmo, porém deve ser pensado como um fim em si mesmo, afinal ele possui dignidade cujo valor é absoluto ${ }^{10}$.

Em outras palavras, se comparar-se valores morais com uma grande construção, é certo que a dignidade será tida como a fundação, a base, o alicerce. Não possuindo preço, nem sendo intransferível, e nas palavras de Kant, é pautado na valorização do homem como fim em si e não como meio ou objeto para alcançar outros objetivos.

Maria Celina Bodin de Moraes, ao parafrasear Kant, ensina:

No mundo social existem duas categorias de valores: o preço (preis) e a dignidade (Würden). Enquanto o preço representa um valor exterior (de mercado) e manifesta interesses particulares, a dignidade representa um valor interior (moral) e é de interesse geral. As coisas têm preço; as pessoas, dignidade. $\mathrm{O}$ valor moral se encontra infinitamente acima do valor de mercadoria, porque, ao contrário deste, não admite ser substituído por equivalente. Daí a exigência de jamais transformar o homem em meio para alcançar quaisquer fins. Em consequência, a legislação elaborada pela razão prática, a vigorar no mundo social, deve levar em conta, como sua finalidade máxima, a realização de valor intrínseco da dignidade humana $^{11}$

6 SARLET, Ingo Wolfgang. Dignidade da pessoa humana - parte II. In: BARRETTO, Vicente de Paulo (Coord.).

Dicionário de filosofia do direito. São Leopoldo: Editora Unisinos, 2006. p. 223.

7 CAVALCANTE, Benigno. Evolução dos direitos da personalidade no Brasil. Cascavel, PR: Assoeste, 2009. p.50.

8 TOMÁS DE AQUINO. Suma Teológica, I, 29, 3

9 KANT, Immanuel GrundlegungzurMetaphysik der Sitten. Tradução Paulo Quintela: Fundamentação da metafísica dos costumes. São Paulo, SP: Abril Cultural, 1980. (Coleção “Os Pensadores”), p. 135-140.

10 KANT, Immanuel. A metafísica dos costumes. Tradução de Edson Bini. 2. ed. Bauru, SP: Edipro, 2008. p. 276

11 MORAES, Maria Celina Bodin. O conceito de dignidade humana: substrato axiológico e conteúdo normativo. In: SARLET, Ingo Wolfgang (organizador). Constituição, direitos fundamentais e direito privado. 2. ed. Porto Alegre: Livraria do Advogado, 2006. p. 115-116. 
Além do ser humano ter valor moral intransferível percebe-se que a pessoa é portadora da dignidade pelo simples fato de ser pessoa, e se apodera deste princípio tido como o primeiro de todos, é o primordial. Também contida no tecido social, ético e mora ${ }^{12}$ quando se compara ao DNA das células, sendo a energia propulsora do homem.

Foi no período pós-guerra que o mundo se viu numa situação desconfortante e de necessidade imediata para tornar algo intrínseco ao homem, de sua personalidade, de seu interior, necessidade essa que culminou na Declaração Universal dos Direitos Humanos de 1948 que sem engodo traz logo no seu primeiro artigo "Todos os homens nascem livres e iguais em dignidade e direitos", ou seja, não se trata de algo dado de presente como recompensa ao ser humano e por isso foi tipificado, pelo contrário, antes de constar em qualquer código, estatuto ou declaração, a dignidade já existia, desde que o homem é homem, pois se trata de sua essência. Então, tal Declaração veio de forma clara e objetiva, demonstrando tamanha necessidade de afirmar, defender e proteger ${ }^{13}$ a dignidade da pessoa humana.

Nota-se que o conceito da dignidade da pessoa humana está em construção, uma vez que é embasado nos Direitos Humano, e este por sua vez tende a proteger todos os indivíduos. Desde a sua concepção o ser humano possui direitos, inclusive a ampla proteção à sua dignidade, ou seja, possui dignidade pelo simples fato de ser pessoa humana.

A Constituição da República Federativa do Brasil de 1988 foi inspirada dentre tantas, na Declaração supracitada, e para a população nacional, tal defesa da Dignidade da Pessoa Humana é o elo do Estado Democrático de Direito. A pessoa humana, tem capacidade para desenvolver várias áreas protegidas pelo Estado, como a relação familiar e as obrigações das pessoas que compõe as mais distintas formas de família hodiernamente.

Deve-se considerar que é a entidade familiar o local onde se deve reconhecer, antes de qualquer outro meio, os direitos fundamentais de todo ser humano desde sua concepção, ou seja, a família configura importantíssima dimensão de direitos humanos, devendo de forma solícita promover o respeito ao princípio. De forma direta, após a intangibilidade da vida humana, tem-se como produto imediato do princípio da dignidade humana o respeito pela integridade física e psíquica da pessoa ${ }^{14}$, é na entidade familiar que a dignidade humana alcança terreno para florescer ${ }^{15}$.

A família é tida como uma instituição que permeia os mais intrínsecos sentimentos, pensamentos, desejos de cada pessoa, e não deve ser considerada apenas a célula mater da sociedade, mas também um protótipo para outros tipos de estrutura e instituições ${ }^{16}$. Também pode ser considerada como um meio para o fiel desenvolvimento do que se entende como personalidade humana e também absoluta consolidação de cada membro, pois pelo entendimento

12 DWORKIN, Ronald. A raposa e o porco-espinho: justiça e valor. São Paulo: Martins Fontes, 2014. p.149

13 MOURA, Laércio Dias de. A dignidade da pessoa e os direitos humanos: $O$ ser humano num mundo em transformação. Bauru, SP: EDUSC; São Paulo: Loyola; Rio de Janeiro: PUC, 2002, p. 74.

14 AZEVEDO, Antonio Junqueira de. Caracterização jurídica da dignidade da pessoa humana. Revista dos Tribunais, São Paulo, ano 91, n. 797.março. 2002. p.21

15 DIAS, Maria Berenice. Manual de Direito das Famílias. Porto Alegre: Livraria do Advogado, 2005, p. 58.

16 GROENINGA, Giselle Câmara. Direito e Psicanálise: Um novo horizonte epistemológico. In: PEREIRA, Rodrigo da Cunha (Coord.). Afeto, Ética, Família e o novo Código Civil. Belo Horizonte: Del Rey, 2004, p. 258. 
de Farias, é no seio familiar que há de ocorrer os fatos elementares da vida do ser humano, sejam quais forem, como decisões profissionais, resolução de problemas, apreciação do sucesso, etc. ${ }^{17}$; devendo ser entendida pela formação por laços de afetividade e imposição do que se chamam hoje em dia, condutas éticas ${ }^{18}$.

Pelo viés constitucional, o surgimento de novos valores responsáveis pelas modificações do seio familiar, evoluiu para a família que não depende da obrigatoriedade do casamento, é necessário que haja um planejamento familiar de forma responsável, e juntamente com o Estado, a família é reconhecida como provedora de direito ${ }^{19}$. No entendimento de Cristiano Farias ao identificar e afirmar que "a família existe em prol de seus membros e não seus membros em função da família, o que dá a aqueles a função de reconhecer a pessoa humana e servir de fato, verdadeiramente como local próprio para que a dignidade seja promovida", como uma das finalidades à alcançar a felicidade e permitir o surgimento de esperanças, concretização de valores e alicerce para todos os $\operatorname{casos}^{20}$.

A eficácia do princípio da dignidade humana envolve a concordância que à cada pessoa de forma singular, é atribuído tudo que aquilo que faz parte de sua individualidade, há de pensar que quando o tocante é relação parental, existe aí uma dignidade dos coparticipes, cujo fundamento precisa ser o respeito bilateral, construção conjunta, diálogo a todo momento com o outro, edificando assim o seio familiar e fortificando a afetividade. E ainda nesse viés, o que tem ocorrido em âmbito doutrinário nos últimos tempos é a necessidade de enfatizar o caráter intersubjetivo e relacional da dignidade humana ${ }^{21}$, sempre voltando para o dever de cada integrante em sempre respeitar cada ser humano, e além disso, defender seus direitos fundamentais.

É necessário atentar-se que em tempos de pós-modernidade onde há de certo modo um abandono de princípios e valores morais, éticos, religiosos, etc., mesmo que se tenha no ordenamento jurídico pátrio certas questões que guardam e protegem a dignidade humana, bem como o direito à afetividade, o exercício desta modalidade tem se feito de forma limitada e a sociedade já vem sentindo as consequências do que Zygmunt Bauman chama de Amor Líquido, que será tratado no próximo capítulo. O poder familiar tem sido relativizado dia após dia, e também tem sido constatado que laços fraternos e parentais precisam se dar de forma mais importante, alimentando o afeto, servindo a dignidade humana aqueles que ainda são pequenos dependentes.

\section{CRISE DO AMOR LÍQUIDO SEGUNDO ZYGUMMAT BAUMAN}

Será possível dizer que a humanidade já viveu tudo o que podia viver e agora sente a necessidade de se reinventar? Ou em outra hipótese, levados por incontáveis experiências frustrantes das mais variadas áreas da vida, decidiu cada um, na sua individualidade, dentro de

17 FARIAS, Cristiano Chaves de. Escritos de Direito de Família. Rio de Janeiro: Lumen Juris, 2007. p.132.

18 NALINI, José Renato. Ética geral e profissional. 3. ed. São Paulo: Revista dos Tribunais, 2001, p. 111-112.

19 VENCELAU, Rose Melo. O elo perdido da filiação: Entre a verdade jurídica, biológica e afetiva no estabelecimento do vínculo paterno-filial. Rio de Janeiro: Renovar, 2004, p. 45.

20 FARIAS, Cristiano Chaves de. Escritos de Direito de Família. Rio de Janeiro: Lumen Juris, 2007. p.136.

21 HABERMAS, Jürgen. O futuro da natureza humana. Trad. de Karina Jannini. São Paulo: Martins Fontes, 2004. p.49-51. 
si mesmo, recalcular a rota da sua vida em busca da felicidade? Se sim, ou se não, para todas as perguntas, a sociedade contemporânea, a nível mundial tem vivido épocas conturbadas, pouco se importando com o futuro.

São ações inconsequentes do homem a degradar o meio ambiente sem pensar no dia de amanhã. Milhares de quilômetros de florestas são devastados ${ }^{22}$. Resíduos químicos são lançados mar a dentro por grandes corporações, e até mesmo o beira-mar, poluído por lixo doméstico ${ }^{23}$ por turistas inconsequentes. São sistemas de governos falidos, sistemas econômicos fracassados, e sistema político corrompido. Seria o fim? Não se ficasse apenas por aí. Pessoas são escravizadas, crianças são impostas à prostituição, famílias todos os dias são despedaçadas por assassinatos - desde acidental por imprudência, como por rixas de facções, traficantes versus policiais.

O bem mais precioso do ser humano, é a vida, porém, passa a valer pouco, quase nada. Que dirá sua dignidade? Enquanto boa parte da população tem trabalhado $44 \mathrm{~h}$ por semana (não esquecendo dos trabalhadores informais que possuem mais de 3 empregos), sem contar tempo de deslocamento entre casa e trabalho, e quando chega em casa só quer assistir à sua série favorita, perdendo-se o contato, os olhos nos olhos, o abraço apertado, a janta na mesa. O grande herói é o relacionamento, segundo Bauman. ${ }^{24}$

O sociólogo em questão, afirma que existe uma modalidade de homem, chamado o homem sem vínculos ${ }^{25}$, uma vez que esta última característica o torna menos indefeso. A relação tida como afetiva é tida por ambivalente. Há um duelo entre desejar ter amor eterno e uma segurança de vida, enquanto do outro lado há o receio de perder outra oportunidade por estar preso em outra situação. E com esse pensamento, a vida passa cada vez mais sem sentido, sem relacionamento, sem base, valores e dignidade humana.

Com a intenção de descrever a relação do ser humano com o ato de consumir, Bauman diz "tal como outros bens de consumo, ela deve ser consumida instantaneamente (não requer maiores treinamentos nem uma preparação prolongada) e usada uma só vez, "sem preconceito". É, antes de mais nada, eminentemente descartável. ${ }^{26 "}$. Em outras palavras, as relações hodiernamente obedecem ao princípio do consumismo, na qual o uso e descarte acontecem de forma cada vez mais voraz e frenética. Bauman citando Harvie Ferguson afirma que:

Os consumidores hoje não compram para satisfazer um desejo, como observou Harvie Ferguson - compram por impulso. Semear, cultivar e alimentar o desejo leva tempo (um tempo insuportavelmente prolongado para os padrões de uma

22 SENRA, Ricardo. Áreas de conservação desmatadas na Amazônia estão perdendo proteção do governo, aponta estudo nos EUA. BBC News. Disponível em: $<$ https://www.bbc.com/portuguese/brasil-43126758> Acesso em: 13 abr. 2019.

23 AMOS, Jonathan. Oceanos 'recebem 8 milhões de toneladas de plástico por ano'. BBC News. Disponível em: $<$ https://www.bbc.com/portuguese/noticias/2015/02/150213 plastico mares lk> Acesso em: 13 abr. 2019.

24 BAUMAN, Zygmunt. Amor líquido: sobre a fragilidade dos laços humanos. Rio de Janeiro: Jorge Zahar. Ed. 2004. p.9.

25 BAUMAN, Zygmunt. Amor líquido: sobre a fragilidade dos laços humanos. Rio de Janeiro: Jorge

Zahar. Ed. 2004. p.48.

26 BAUMAN, Zygmunt. Amor líquido: sobre a fragilidade dos laços humanos. Rio de Janeiro: Jorge Zahar. Ed. 2004,p.22. 
cultura que tem pavor em postergar, preferindo a "satisfação instantânea"). O desejo precisa de tempo para germinar, crescer e amadurecer. Numa época em que o "longo prazo" é cada vez mais curto, ainda assim a velocidade de maturação do desejo resiste de modo obstinado à aceleração ${ }^{27}$.

$\mathrm{O}$ vínculo ou laço entre as pessoas passam a se tornarem atitudes que brigam entre si, como diz Bauman "relacionamento é o assunto mais quente do momento, e aparentemente o único jogo que vale a pena, apesar de seus óbvios ${ }^{28}$ ". Enquanto o ser humano encontra satisfação em seus relacionamentos, mantém-se nele, porém quando acaba sua satisfação, sem pensar duas vezes, desapega de um relacionamento e vai em busca de outro. Se este relacionamento é tido como "amor", percebe-se a inconstância, veracidade em se amar de uma forma imensamente proporcional ao deixar de amar. Existe uma dualidade dentro do ser humano que muitas vezes anseia precisar dos outros, viver em comunidade, depender de sua família, entregar seu coração para a pessoa amada, mas de outro lado, logo se percebe o grande medo em realizar tudo isso e se tornarem imóveis em um mundo de complexas mudanças cotidianamente.

Tudo é visto como temporário. Carros, casas, eletrodomésticos com durabilidade incrivelmente menores do que a 30 anos atrás, roupas, alimentos "não perecíveis", e agora, mais do que nunca, relacionamentos. Amizades, namoros, casamentos. Se não é útil, não se é preciso gastar tempo; se não me causa prazer, para que manter? Se não me traz felicidade, é perca de tempo. E assim, olhos nos olhos vão ficando cada vez mais distantes e substituídos por redes sociais com mais de mil amigos. Seria possível manter amizade com essa quantidade de pessoas? A não ser que esta amizade seja tão frágil como uma casca de ovo, absolutamente frágil. Mas no tocante à fragilidade, quem se importa? Não há preocupação com a dor do outro, apenas com a sua própria vida, e então o egocentrismo e o individualismo ganha forma, e se pensa no próprio 'eu', todo trabalho, estudo, acúmulo de riquezas é para satisfazer uma suposta segurança e garantir uma rápida e momentânea felicidade, que logo será substituída pelo que o mercado capitalista oferecer.

Citando Sócrates, ao dizer que o amor se dirige ao gerar e ao nascer do que é belo, entende-se que o mais que um sentimento, o amor é transcendência, que mais de um belo significado, seu início provém de coisas concebidas pelo exclusivo sentimento. Porém, com a natureza individualista permeando o homem na era pós-moderna, o ato de ceder a outro em relacionamento é caracterizado por algo que tirará esta tal individualidade, quem dirá então dizer "até que a morte nos separe":

[...] Afinal, a definição romântica do amor como "até que a morte nos separe" está decididamente fora de moda, tendo deixado para trás seu tempo de vida útil em função da radical alteração das estruturas de parentesco às quais costumava servir e de onde extraia seu vigor e sua valorização. Mas o desaparecimento dessa noção significa, inevitavelmente, a facilitação dos testes pelos quais uma

27 BAUMAN, Zygmunt. Amor líquido: sobre a fragilidade dos laços humanos. Rio de Janeiro: Jorge Zahar. Ed. 2004, p.21.

28 BAUMAN, Zygmunt. Amor líquido: sobre a fragilidade dos laços humanos. Rio de Janeiro: Jorge Zahar. Ed. 2004, p. 10. 
experiência deve passar para ser chamada de "amor": Em vez de haver mais pessoas atingindo mais vezes os elevados padrões do amor, esses padrões foram baixados. Como resultado, o conjunto de experiências às quais nos referimos com a palavra amor expandiu-se muito. Noites avulsas de sexo são referidas pelo codinome de "fazer amor". (BAUMAN, 2004, p. 19).

A necessidade de apaixonar-se se tornou raro e ineficiente. Seguindo a linha de pensamento da cultura hodierna, não é mais necessário ser usado como elemento de intrínseca necessidade, afinal, para quem pensa em desapegar antes de se apegar, pouco se importa com qualquer sentimento que lhe causará qualquer tipo de fraqueza. A frase "Até que a morte nos separe", é deixada apenas para filmes de romance e a necessidade de consumo exacerbado chega na seara dos relacionamentos. Outro termo que remonta atenção é "relacionamento puro", o qual é tido como predominante onde as partes não questionam em buscar o que cada um pode ganhar, mas as partes também insistem enquanto entendem que podem oferecer satisfações suficientes para permanecerem na relação ${ }^{29}$.

Neste ínterim, não se pode deixar de notar que no mundo atual, os relacionamentos líquidos intercalam-se com os atributos trabalhistas versus ente familiar, uma vez que a relação entre pais e filhos, juntamente com sua afetividade, sofre com a ausência de tempo, privação de contato humano. Então desde a falta de constância e pseudonecessidade de consumo exagerado, até à míngua relação humana, os lares passam a ser as novas vítimas dessa sociedade cujo amor está cada vez mais líquido. Local onde deveria proporcionar um ambiente saudável para um amplo desenvolvimento da criança, seja pessoal, emocional, físico, etc., deixa de proteger e exercer a dignidade da pessoa humana.

"O individualismo, que em seu sentido positivo significa libertação das cadeias sociais, significa, no sentido negativo, auto propriedade, o direito - e o dever - de investir a própria energia no sucesso da própria pessoa" ${ }^{30}$. E cada vez o constrangimento em se ter unidade perde espaço para o sucesso do individualismo onde "a mudança de funções acarreta uma mudança de natureza: na verdade, a família deixa de ser uma instituição forte; sua privatização é uma desinstitucionalização. A sociedade se encaminha para famílias informais". ${ }^{31}$

Seja por mecanismos conscientes ou inconscientes, a família tem papel preponderante na formação e aperfeiçoamento da personalidade, bem como da dignidade do ser humano, então quando se nota que o esvaziamento da entidade familiar tem ocorrido de forma cada vez mais comum, surge a preocupação com a sociedade que será formada em consequência a essa relação superficial, desestruturada e desafetada. O perigo de fazer com que filhos se tornem objetos de consumo emocional ${ }^{32}$ revela que o ser humano se encontra em situação deplorável, deixando de lado o prazer e o descobrimento paternal, afinal ao optar ter filho, antes é necessário

29 BAUMAN, Zygmunt. Amor líquido: sobre a fragilidade dos laços humanos. Rio de Janeiro: Jorge Zahar. Ed. 2004, p.79.

30 Fromm, Erich. Ter ou Ser? Tradução de Nathanael C. Caixeiro. 4. ed. São Paulo: LTC, 1987. p. 83.

31 Prost, Antoine. A família e o indivíduo. In: PROST, Antoine; VINCENT, Gérard (Orgs.). História da vida privada. São Paulo: Companhia das letras, 1992. v. 5, p. 61.

32 BAUMAN, Zygmunt. Amor líquido: sobre a fragilidade dos laços humanos. Rio de Janeiro: Jorge Zahar. Ed. 2004,p.43. 
avaliar o contentamento de um ser mais fraco e dependente.

Deve-se cogitar que num mundo de aparências e cópias, as vidas de pessoas midiáticas não são perfeitas como se vê nas redes sociais. Pelo contrário, elas são pagas para parecerem sempre felizes, cuidando de seus filhos perfeitos, com seus animais de estimação e mega casas. Se reproduzir no outro com intenção de ser como o outro é não passa de uma falta de identidade pessoal, que valoriza muito mais o ter do que o ser. De modo algum o homem deve comparar um outro ser humano com as qualidades supracitadas, a objetos de consumos rápidos e descartáveis.

Tratar de um ser humano, com qualidades incontáveis, vestido de dignidade intrínseca a ele, deve-se no mínimo de grande aprendizado, mas jamais comparado ao ato de descartar e muito menos negar o afeto seja a quem for, muito menos a alguém vulnerável em todos os sentidos. Dessa forma, Bauman entende que o homem precisa com certa urgência, diligenciar uma nova humanidade para agregar projetos individuais e ações coletivas, recomeçando e recalculando a rota o quanto antes.

\section{CONSIDERAÇÕES FINAIS}

Entende-se ser impossível conceituar ou delimitar a dignidade da pessoa humana, afinal se trata de um princípio norteador, de um valor moral e espiritual atrelado e inerente à pessoa humana. Tida como um conceito a priori, ou seja, independentemente de sua positivação na legislação, tida como valor próprio da natureza do homem.

A primeira ideia de dignidade humana é a de que Deus criou o homem segundo a sua imagem e semelhança e o cristianismo trouxe Deus doando seu único filho para salvar a humanidade. Esse valor inexorável, de maneira alguma poderia ter sua essência alterada para um simples objeto.

A dignidade é tida como a fundação, a base, o alicerce. Contida no tecido social, ético e moral quando se compara ao DNA das células, sendo a energia propulsora do homem. Sendo pautada na valorização do homem como fim em si e não como meio ou objeto para alcançar outros objetivos.

Com o surgimento da Declaração Universal dos Direitos Humanos de 1948, a dignidade humana foi tutelada. No seu primeiro artigo, estabelece "Todos os homens nascem livres e iguais em dignidade e direitos", inúmeros países foram influenciados, inclusive o Brasil, que na Constituição de 1988 adotou em seu artigo $1^{\circ}$, inciso III, onde o princípio da dignidade humana é fundamento, com valor incalculável e primordial. Não podendo desconsiderar que este princípio em tela é o elo de todos os direitos fundamentais.

$\mathrm{O}$ Estado tem responsabilidade direta na tutela do direito à dignidade da pessoa humana, todavia, o presente artigo também atenta para a análise da responsabilidade direta da família na formação e proteção da pessoa, mais especificamente, na criança, que não possui independência e é a parte mais frágil dos entes familiares. 
A entidade familiar é o local onde se deve reconhecer, antes de qualquer outro meio, os direitos fundamentais de todo ser humano desde sua concepção, ou seja, a família configura importantíssima dimensão de direitos humanos, devendo de forma solícita promover o respeito ao princípio. Porém, com vistas a teoria do amor líquido de Zygmunt Bauman, percebeuse que por decorrências de inúmeros fatores, as relações humanas estão cada vez mais fragilizadas, fragmentadas e descartadas. O ser humano cada dia mais tem se preocupado apenas em adquirir bens, consumi-los e descartá-los, chegando a ponto de tratar relacionamentos amorosos, como rápidas situações prazerosas, e ao findar deste, se livrará daquele.

Coisas são tratadas como coisas, pessoas são tratadas como coisas, e filhos de relacionamentos egoístas passam a ser tratados como coisas. Sendo então o local onde deveria proporcionar um ambiente saudável para um amplo desenvolvimento da criança, seja pessoal, emocional, físico, etc., deixa de proteger e exercer a dignidade da pessoa humana.

A família tem papel de suma importância na formação e aperfeiçoamento da personalidade, bem como da dignidade do ser humano. O perigo de fazer com que filhos se tornem objetos de consumo emocional revela que o ser humano se encontra em situação deplorável.

Os desafios atuais foram lançados, a geração hodierna precisa unir suas necessidades com a insegurança de se ter um vínculo sólido, com bases sólidas, que gerarão frutos sólidos. Bauman entende que o homem precisa com certa urgência, diligenciar uma nova humanidade para agregar projetos individuais e ações coletivas, recomeçando e recalculando a rota o quanto antes. Em um local de incertezas, nasce uma imensa necessidade de autorreflexão da humanidade frente à crise atual.

\section{REFERÊNCIAS BIBLIOGRÁFICAS}

AMOS, Jonathan. Oceanos 'recebem 8 milhões de toneladas de plástico por ano'. BBC News. Disponívelem: $<$ https://www.bbc.com/portuguese/noticias/2015/02/150213_plastico_mares_lk $>$ Acesso em: 13 abr. 2019.

AZEVEDO, Antônio Junqueira de. Caracterização jurídica da dignidade da pessoa humana. Revista dos Tribunais, São Paulo, ano 91, n. 797. 2002.

DIAS, Maria Berenice. Manual de Direito das Famílias. Porto Alegre: Livraria do Advogado, 2005.

BARCELLOS, Ana Paula de. A eficácia jurídica dos princípios constitucionais: o princípio da dignidade da pessoa humana. Rio de Janeiro: 2002.

BAUMAN, Zygmunt. Amor líquido: sobre a fragilidade dos laços humanos. Rio de Janeiro: Jorge Zahar. Ed. 2004.

BRASIL. Constituição Federal de 1988. Brasília, 1988. Disponível em: < hhttp://www.planalto. gov.br/ccivil_03/Constituicao/Constituicao.htm >. Acesso em: 18 abr. 2019.

Dicionário Aurélio. Disponível em: https://dicionariodoaurelio.com/dignidade. Acesso em: 02 mar 2019. 
BRASIL. Constituição (1988). Constituição da República Federativa do Brasil. Brasília

CAVALCANTE, Benigno. Evolução dos direitos da personalidade no Brasil. Cascavel, PR: Assoeste, 2009.

DWORKIN, Ronald. A raposa e o porco-espinho: justiça e valor. São Paulo: Martins Fontes, 2014.

FARIAS, Cristiano Chaves de. Escritos de Direito de Família. Rio de Janeiro: Lumen Juris, 2007.

Fromm, Erich. Ter ou Ser? Tradução de Nathanael C. Caixeiro. 4. ed. São Paulo: LTC, 1987

GAMA, Guilherme Calmon Nogueira da. O biodireito e as relações parentais: $\mathbf{O}$ estabelecimento da parentalidade-filiação e os efeitos jurídicos da reprodução assistida heteróloga. Rio de Janeiro: Renovar, 2003.

GROENINGA, Giselle Câmara. Direito e Psicanálise: Um novo horizonte epistemológico. In: PEREIRA, Rodrigo da Cunha (Coord.). Afeto, Ética, Família e o novo Código Civil. Belo Horizonte: Del Rey, 2004.

HABERMAS, Jürgen. O futuro da natureza humana. Trad. de Karina Jannini. São Paulo: Martins Fontes, 2004.

KANT, Immanuel. A metafísica dos costumes. Tradução de Edson Bini. 2. ed. Bauru, SP: Edipro, 2008.

KANT, Immanuel GrundlegungzurMetaphysik der Sitten. Tradução Paulo Quintela: Fundamentação da metafísica dos costumes. São Paulo, SP: Abril Cultural, 1980.

MORAES, Maria Celina Bodin. O conceito de dignidade humana: substrato axiológico e conteúdo normativo. In: SARLET, Ingo Wolfgang (organizador). Constituição, direitos fundamentais e direito privado. 2. ed. Porto Alegre: Livraria do Advogado, 2006.

MOURA, Laércio Dias de. A dignidade da pessoa e os direitos humanos: O ser humano num mundo em transformação. Bauru, SP: EDUSC; São Paulo: Loyola; Rio de Janeiro: PUC, 2002.

NALINI, José Renato. Ética geral e profissional. 3. ed. São Paulo: Revista dos Tribunais, 2001. Prost, Antoine. A família e o indivíduo. In: PROST, Antoine; VINCENT, Gérard (Orgs.). História da vida privada. São Paulo: Companhia das letras, 1992.

TOMÁS DE AQUINO. Suma Teológica, v. I. 1485.

SARLET, Ingo Wolfgang. Dignidade da pessoa humana - parte II. In: BARRETTO, Vicente de Paulo (Coord.). Dicionário de filosofia do direito. São Leopoldo: Editora Unisinos, 2006.

SENRA, Ricardo. Áreas de conservação desmatadas na Amazônia estão perdendo proteção do governo, aponta estudo nos EUA. BBC News. Disponível em: $<$ https://www.bbc.com/ portuguese/brasil-43126758> Acesso em: 13 abr. 2019. 
VENCELAU, Rose Melo. O elo perdido da filiação: Entre a verdade jurídica, biológica e afetiva no estabelecimento do vínculo paterno-filial. Rio de Janeiro: Renovar, 2004.

Recebido em: 23/04/2019.

Aprovado em: 03/06/2019. 